OPEN ACCESS

Edited by:

Robert L. Lins,

Independent researcher, Antwerp,

Belgium

Reviewed by:

Hussein Kadhem Al-Hakeim,

University of Kufa, Iraq

Ponlapat Rojnuckarin,

Chulalongkorn University, Thailand

Sjaak Philipsen,

Erasmus Medical Center, Netherlands

*Correspondence:

Yongrong Lal

laiyongrong@263.net

Rongrong Liu

liurongrong@stu.gxmu.edu.cn

${ }^{t}$ These authors have contributed equally to this work and share first

authorship

Specialty section:

This article was submitted to

Drugs Outcomes Research and

Policies,

a section of the journal

Frontiers in Pharmacology

Received: 13 November 2021

Accepted: 17 December 2021

Published: 11 January 2022

Citation:

Lu Y, Wei Z, Yang G, Lai Y and Liu R (2022) Investigating the Efficacy and

Safety of Thalidomide for Treating Patients With B-Thalassemia: A Meta-

Analysis.

Front. Pharmacol. 12:814302.

doi: 10.3389/fphar.2021.814302

\section{Investigating the Efficacy and Safety of Thalidomide for Treating Patients With B-Thalassemia: A Meta-Analysis}

\author{
Yanfei Lu ${ }^{\dagger}$, Zhenbin $\mathrm{Wei}^{\dagger}$, Gaohui Yang, Yongrong Lai* and Rongrong Liu *
}

Department of Hematology, The First Affiliated Hospital of Guangxi Medical University, Nanning, China

At present, the main therapies for $\beta$-thalassemia patients include regular blood transfusion and iron chelation, associating with a number of limitations. Thalidomide, a fetal hemoglobin $(\mathrm{HbF})$ inducer that promotes $\gamma$-globin gene expression, has been reported to be effective for $\beta$-thalassemia. Thus, this meta-analysis was conducted to assess the efficacy and safety of thalidomide for treating patients with $\beta$-thalassemia. We searched the related studies from eight databases published from inception until December 1, 2021. The R 4.0.5 language programming was used to perform meta-analysis. After screening of retrieved articles, 12 articles were included that enrolled a total of 451 patients. The Cochrane Collaboration risk assessment tool was used to evaluate the quality and the bias risk of the randomized controlled trials (RCTs), and non randomized trials were assessed using Newcastle-Ottawa Scale (NOS). After treatment with thalidomide, the pooled overall response rate (ORR) was 85\% (95\% confidence interval (Cl): 80-90\%), and the pooled complete response rate (CRR) was 54\% (95\% confidence interval: 31-76\%). Compared with the placebo group, the thalidomide group had higher odds of overall response rate (odds ratio $=20.4 ; 95 \% \mathrm{Cl:} 6.75-61.64$ ) and complete response rate (odds ratio $=20.4$; 95\% Cl: 6.75-61.64). A statistically significant increase in hemoglobin level and $\mathrm{HbF}$ level after treatment, while there was no statistically significant difference in adult hemoglobin $(\mathrm{HbA})$ level, spleen size, and serum ferritin. According to the results of ORR and CRR, transfusion-dependent thalassemia (TDT) patients showed remarkable efficacy of thalidomide, 83 and 52\% respectively. So we analyzed 30 transfusion-dependent thalassemia patients from three studies and found that the most frequent $\beta$-globin gene mutations were CD41-42 (-TCTT), while response to thalidomide did not show any statistically significant relationship with Xmnl polymorphism or CD41-42 (-TCTT) mutation. About $30 \%$ of patients experienced mild adverse effects of thalidomide. Collectively, thalidomide is a relatively safe and effective therapy to reduce the blood transfusion requirements and to increase $\mathrm{Hb}$ level in patients with $\beta$-thalassemia.

Keywords: thalidomide, $\beta$-thalassemia, meta-analysis, hemoglobin level, therapy 


\section{INTRODUCTION}

$\beta$-thalassemia comprises a group of hereditary hematological disorders characterized by abnormalities in the synthesis of the $\beta$ chains of hemoglobin. With the migration of populations, nearly $5 \%$ of the world's population carry mutations of globin genes (Angastiniotis and Modell, 1998). It was estimated that about $1.5 \%$ of the global population ( $80-90$ million people) are carriers of $\beta$-thalassemia (Modell and Darlison, 2008). The basic defect in $\beta$-thalassemia is an imbalanced relationship between the alpha globin and beta globin chains caused by a reduced or absent production of $\beta$-globin chains. An excess unmatched $a$-globin chain precipitates in erythropoiesis, resulting in elevated mechanical stresses and oxidative damage to erythropoiesis in patients with $\beta$-thalassemia. The clinical severity of $\beta$-thalassemia is related to the extent of an imbalanced relationship between the alpha globin and non-alpha globin chains, resulting in variable phenotypes, ranging from severe anemia to clinically asymptomatic individuals.

At present, $\beta$-thalassemia seriously threatens public health, and the main therapies for patients with $\beta$-thalassemia include regular blood transfusion and iron chelation. However, long-term blood transfusion can cause iron overload and also spread transfusion-related infectious diseases. Adverse effects (AEs) of iron-chelating agents have also been reported. Because of the decrease in blood donation rates caused by the coronavirus disease 2019 pandemic, the global demand of blood products exceeds supply. Blood transfusion in patients with $\beta$-thalassemia is associated with difficulties. Hematopoietic stem cell transplantation (HSCT) is the primary method to cure patients with $\beta$-thalassemia, while due to the high level of HLA polymorphism, the major obstacle in the HSCT is to find a donor with perfectly matched HLA antigens. Recently, gene therapy and gene editing techniques have assisted clinicians to treat $\beta$-thalassemia, while they have not been popularized globally. In addition to traditional treatments, novel therapies for $\beta$-thalassemia have been presented. Activin receptor ligand traps are also effective in treating anemia associated with $\beta$-thalassemia (Suragani et al., 2014). In 2019, the United States Food and Drug Administration approved luspatercept for treating anemia in adult patients with $\beta$-thalassemia. Other therapies, such as Janus kinase 2 (JAK2) inhibitor, have been previously reported to improve iron dysregulation and reduce synthesis of a-globin chain.

Despite advances achieved in the therapy of $\beta$-thalassemia patients, maintaining a high hemoglobin ( $\mathrm{Hb})$ level is still a main challenge. Therefore, there is an urgent need for novel, effective, and safe treatments for $\beta$-thalassemia. Fetal hemoglobin ( $\mathrm{HbF}$ ) inducers have markedly attracted clinicians' attention in recent years, and thalidomide was reported as a promising drug in the treatment of $\beta$ thalassemia. Thalidomide was originally used to stop vomiting in pregnancy, while it has been withdrawn from the market because of its teratogenic effects. It has been reused as an immunomodulatory and anti-angiogenic drug to treat autoimmune diseases. To date, few retrospective studies have pointed out that thalidomide, as a strong $\mathrm{HbF}$ inducer, could improve the clinical symptoms and the quality of life of patients with $\beta$-thalassemia.

The efficacy of thalidomide in human models has not been comprehensively determined, and there is a certain degree of uncertainty. The present meta-analysis aimed to assess the efficacy and safety of thalidomide in treating patients with $\beta$ thalassemia.

\section{METHODS}

\section{Search Strategy}

We searched the related studies from PubMed, Web of Science, embase, Cochrane Library, China Biology Medicine disc, China National Knowledge Infrastructure, Wanfang, and VIP Data Knowledge Service Platform published from inception until December 1, 2021. The following terms were searched: ("Thalidomide") OR (Sedoval [All Fields]) OR (Thalomid)) AND ((“Thalassemia") OR (Thalassemia [All Fields])). The protocol has been registered in the International Prospective Register of Systematic Reviews (PROSPERO; Registration No. CRD42014010138).

\section{Inclusion and Exclusion Criteria}

The inclusion criteria were as follows: 1) studies conducted prospectively or retrospectively; 2) patients who were diagnosed with $\beta$-thalassemia; and 3 ) if a study included two or more groups to compare thalidomide with other treatments for primary diseases, such as hydroxyurea, erythropoietin, etc., the group of treatment with thalidomide was included.

The exclusion criteria were as follows: 1) thalidomide combined with other treatments for primary diseases; 2) patients who underwent therapies for less than 3 months. If a study included patients who underwent therapies for $\geq 3$ and $<3$ months, patients who underwent therapies for $<3$ months were excluded; 3) case reports, reviews, conference abstracts, or in vitro studies; or 4) studies with incomplete data.

\section{Assessment of the Quality of Included Studies}

The Cochrane Collaboration risk assessment tool was used to evaluate the quality and the bias risk of the randomized controlled trials (RCTs). It includes selection bias (random sequence generation and allocation concealment); blinding of participants, personnel, and outcomes assessment; completeness of data; selective outcome reporting; and other potential biases. Based on above domains, we categorised studies as having "low", "unclear" or "high" bias risk. The Newcastle-Ottawa Scale (NOS) was used to assess the non randomized studies. The NOS evaluates three quality parameters (selection, comparability, and outcome) divided across eight specific items. Each item on the scale is scored from one point, except for comparability, which can be adapted to the specific topic of interest to score up to two points. Thus, the maximum for each study is 9. Studies with $<3$ points were at a high risk of bias and were excluded. 


\section{Selection of Eligible Studies and Data Extraction}

Two researchers independently searched and selected the eligible studies. Titles and abstracts of retrieved articles were reviewed to exclude duplicate and irrelevant studies. Then, the full-texts of the remaining articles were read, and eligible studies that met the inclusion criteria but did not meet the exclusion criteria were included. Then, the following data were extracted: the first author's full-name, year of publication, research site (a place where scholars conducted research), type of study, type of disease, utilization of blood transfusion, follow-up data, age of patients, sample size, type of intervention. Any disagreements were resolved by discussion with a third researcher.

\section{Outcomes and Statistical Analysis}

The primary outcomes were overall response rate (ORR), complete response rate (CRR), and $\mathrm{Hb}$ level. The secondary outcomes were $\mathrm{HbF}$ level, adult hemoglobin ( $\mathrm{HbA}$ ) level, spleen length, and adverse effects (AEs) of thalidomide. ORR was defined as $\geq 50 \%$ reduction in transfusion requirement or an increase in $\mathrm{Hb}$ level $\geq 1.0 \mathrm{~g} / \mathrm{dl}$ for transfusion-dependent thalassemia (TDT) patients after thalidomide treatment. For non-transfusion-dependent thalassemia (NTDT) patients, ORR was defined as an increase in $\mathrm{Hb}$ level $\geq 1.0 \mathrm{~g} / \mathrm{dl}$. CRR was defined as complete cessation of regular transfusion.

The $\mathrm{R}$ 4.0.5 language programming was used to perform metaanalysis. We used the $\mathrm{I}^{2}$ statistic to test the heterogeneity among the included studies. $\mathrm{I}^{2} \geq 50 \%$ represented a substantial heterogeneity, thus, the random-effects model was used to perform the analysis; otherwise, the fixed-effects model was utilized. The sensitivity analysis was conducted to explore whether the results are sensitive to exclusion of low-quality studies. Egger's regression test was used to explore the presence of publication bias.

The continuous variables $(\mathrm{Hb}, \mathrm{HbF}, \mathrm{HbA}$, spleen size, and serum ferritin (SF)) were expressed as mean \pm standard deviation (SD). Data presented with $95 \%$ confidence intervals (95\% CIs) were analyzed to estimate the efficacy and AEs. We obtained individual participant data from the principal investigator of Yang et al.'s study. Statistical analyses were performed using SPSS 26.0. The Chi-square test or Fisher's exact test was used to analyze the association of response to thalidomide with XmnI polymorphism and genotypes. $p$-value $<0.05$ was considered statistically significant.

\section{RESULTS}

\section{Study Characteristics}

A total of 109 articles were retrieved from the search strategy. After screening of title, abstract, and full-text of those articles, 12 articles were included for analysis (Chen et al., 2017; Li et al., 2018; Ren et al., 2018; Jain et al., 2019; Begum et al., 2020;

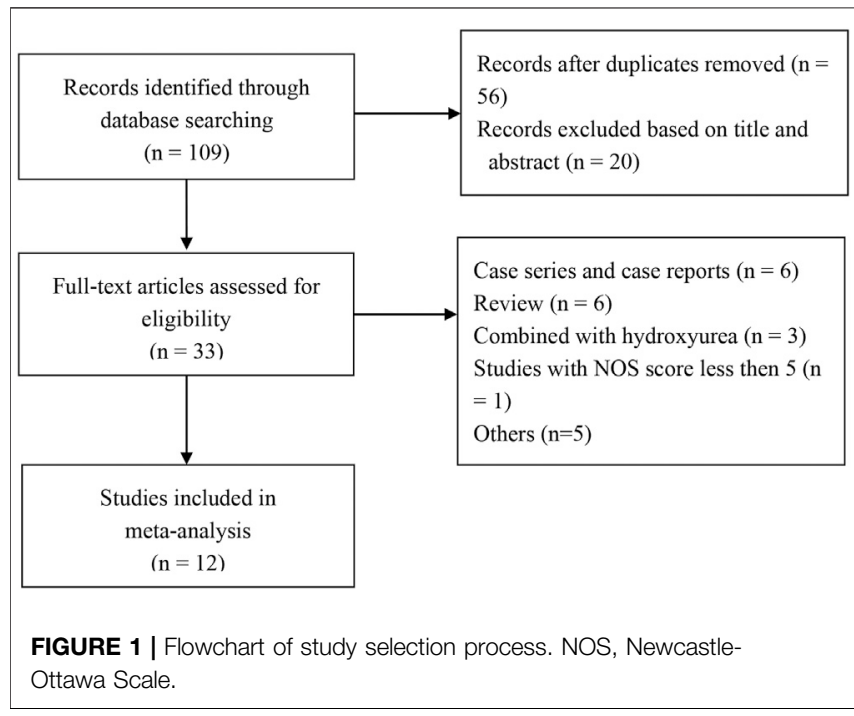

Islam et al., 2020; Nag et al., 2020; Sen et al., 2020; Yang et al., 2020; Yassin, 2020; Chen et al., 2021; Li et al., 2021), which enrolled 451 patients. Jain et al. conducted a RCT and compared hydroxyurea arm with thalidomide arm, while only thalidomide arm was included in the present metaanalysis (Jain et al., 2019). One RCT study and 11 singlearm studies (4 retrospective and eight prospective studies) were included, of which 6 studies were conducted in China, three in India, two in Bangladesh, and one in Iraq. Figure 1 shows flowchart of study selection process according to PRISMA guidelines. Characteristics of the included studies are summarized in Table $\mathbf{1 .}$

\section{QUALITY ASSESSMENT}

The included RCT study was of high-quality through the Cochrane Collaboration risk assessment tool (Supplementary Figures S1,2). Using the NOS, we excluded a study with low quality. All the single-arm studies ranged from five to eight points, which indicated that their quality ranged from medium to high (Supplementary Table S1).

\section{OUTCOMES}

\section{ORR}

ORR was assessed in 10 studies (Chen et al., 2017; Li et al., 2018; Ren et al., 2018; Jain et al., 2019; Nag et al., 2020; Sen et al., 2020; Yang et al., 2020; Yassin, 2020; Chen et al., 2021; Li et al., 2021). Five studies included both TDT and NTDT patients (Chen et al., 2017; Li et al., 2018; Sen et al., 2020; Yang et al., 2020; Yassin, 2020), and the outcomes of TDT and NTDT patients were separated in the original manuscripts, so we analyzed the data in these studies respectively. Chen et al. conducted a RCT included thalidomide group and placebo group (Chen et al., 2021). We not only included the thalidomide group alone to 
TABLE 1 | Characteristics of the included studies.

\begin{tabular}{|c|c|c|c|c|c|c|c|c|c|}
\hline Authors & Year & Country & Design & Disease & Population & $\begin{array}{l}\text { F/U, } \\
\text { month } \\
\text { (range) }\end{array}$ & $\begin{array}{l}\text { Age, } \\
\text { year } \\
\text { (range) }\end{array}$ & $\begin{array}{c}N \\
(M / F)\end{array}$ & Intervention \\
\hline Chen & 2017 & China & $\begin{array}{l}\text { Retrospective } \\
\text { study }\end{array}$ & $\beta$-TM & $\begin{array}{l}\text { NTDT } \\
\text { and TDT }\end{array}$ & 12 & $\begin{array}{c}24 \\
(13-74)\end{array}$ & $9(5 / 4)$ & $\begin{array}{l}\text { Thalidomide (the dose started at } 50 \mathrm{mg} / \mathrm{d} \text { and } \\
\text { increased to } 200 \mathrm{mg} / \mathrm{d} \text { as tolerated) }\end{array}$ \\
\hline $\mathrm{Li}$ & 2018 & China & $\begin{array}{l}\text { Prospective } \\
\text { study }\end{array}$ & $\beta$-TM & $\begin{array}{l}\text { NTDT } \\
\text { and TDT }\end{array}$ & $\begin{array}{l}\text { TDT: }>6 \\
\text { NTDT: }>3\end{array}$ & $\begin{array}{c}29.4 \\
(25-35)\end{array}$ & $7(4 / 3)$ & Thalidomide (the dose was $50 \mathrm{mg} / \mathrm{d}$ ) \\
\hline Ren & 2018 & China & $\begin{array}{l}\text { Prospective } \\
\text { study }\end{array}$ & $\beta$-TM & NTDT & 3 & $\begin{array}{c}25.6 \\
(18-36)\end{array}$ & $\begin{array}{c}14 \\
(8 / 6)\end{array}$ & Thalidomide (the dose was $50 \mathrm{mg} / \mathrm{d}$ ) \\
\hline Jain & 2019 & India & $\begin{array}{l}\text { Prospective } \\
\text { study }\end{array}$ & HbE- $\beta$-TM & NTDT & 6 & $27(7-45)$ & $\begin{array}{c}15 \\
(8 / 7)\end{array}$ & Thalidomide (the dose was $50 \mathrm{mg} / \mathrm{d}$ ) \\
\hline Yassin & 2020 & Iraq & $\begin{array}{l}\text { Prospective } \\
\text { study }\end{array}$ & $\beta$-TM & $\begin{array}{l}\text { NTDT } \\
\text { and TDT }\end{array}$ & $8-36(15)$ & $9(3-43)$ & $\begin{array}{c}37 \\
(21 / 16)\end{array}$ & $\begin{array}{l}\text { Thalidomide (the dose was } 2-10 \mathrm{mg} / \mathrm{kg} / \mathrm{d} \text {, and } \\
\text { a initial dose of } 3 \mathrm{mg} / \mathrm{kg} / \mathrm{d} \text { adjusted to nearest } \\
50 \mathrm{mg} / \mathrm{d} \text { was used) }\end{array}$ \\
\hline Nag & 2020 & India & $\begin{array}{l}\text { Retrospective } \\
\text { study }\end{array}$ & $\mathrm{HbE}-\beta-\mathrm{TM}$ & TDT & 3 & 20 & $\begin{array}{c}21 \\
(7 / 14)\end{array}$ & $\begin{array}{l}\text { Thalidomide (age } \leq 12 \mathrm{Y} \text { : the dose was } 50 \mathrm{mg} / \mathrm{d} \text {; } \\
\text { age }>12 \mathrm{Y} \text { : the dose was } 100 \mathrm{mg} / \mathrm{d} \text { ) }\end{array}$ \\
\hline Islam & 2020 & Bangladesh & $\begin{array}{l}\text { Retrospective } \\
\text { study }\end{array}$ & $\mathrm{HbE}-\beta-\mathrm{TM}$ & TDT & $16(3-38)$ & $15(3-49)$ & $\begin{array}{c}50 \\
(26 / 24)\end{array}$ & Thalidomide (the dose was $50-100 \mathrm{mg} / \mathrm{d}$ ) \\
\hline Begum & 2020 & Bangladesh & $\begin{array}{l}\text { Prospective } \\
\text { study }\end{array}$ & HbE- $\beta$-TM & TDT & 32 & $10(3-24)$ & $\begin{array}{c}51 \\
(28 / 23)\end{array}$ & Thalidomide (the dose was $2-5 \mathrm{mg} / \mathrm{kg} / \mathrm{d}$ ) \\
\hline Sen & 2020 & India & $\begin{array}{l}\text { Prospective } \\
\text { study }\end{array}$ & $\begin{array}{l}\text { HbE- } \beta \text {-TM } \\
\text { and } \beta \text {-TM }\end{array}$ & $\begin{array}{l}\text { NTDT } \\
\text { and TDT }\end{array}$ & $\begin{array}{c}3-11 \\
(7.1 \pm 3.3)\end{array}$ & $15(2-44)$ & $9(6 / 3)$ & Thalidomide (the dose was $50 \mathrm{mg} / \mathrm{d}$ ) \\
\hline Yang & 2020 & China & $\begin{array}{l}\text { Prospective } \\
\text { study }\end{array}$ & $\beta-\mathrm{TM}$ & $\begin{array}{l}\text { NTDT } \\
\text { and TDT }\end{array}$ & $3-37$ & $\begin{array}{c}27.2 \\
(15-45)\end{array}$ & $\begin{array}{c}62 \\
(27 / 35)\end{array}$ & $\begin{array}{l}\text { Thalidomide (the initial dose was } 50 \mathrm{mg} / \mathrm{d} \text {, and } \\
\text { dose of } 100 \mathrm{mg} / \mathrm{d} \text { was given to patients } \\
\text { needing blood transfusions at least twice a } \\
\text { month) }\end{array}$ \\
\hline $\mathrm{Li}$ & 2021 & China & $\begin{array}{l}\text { Retrospective } \\
\text { study }\end{array}$ & $\beta$-TM & TDT & $\begin{array}{l}(14.6 \pm \\
9.6) \geq 6\end{array}$ & $10(5-18)$ & $\begin{array}{c}77 \\
(45 / 32)\end{array}$ & Thalidomide (the dose was $2.5-4$ mg/kg/d) \\
\hline Chen & 2021 & China & $\begin{array}{l}\text { Prospective } \\
\text { study }\end{array}$ & $\beta$-TM & TDT & $\geq 3$ & 18.4 & $\begin{array}{c}99 \\
(62 / 37)\end{array}$ & $\begin{array}{l}\text { Thalidomide (initial dose of } 100 \mathrm{mg} / \mathrm{d} \text { and } \\
\text { escalated to } 150 \mathrm{mg} / \mathrm{d} \text { in } 3 \text { days if no adverse } \\
\text { effects were reported) }\end{array}$ \\
\hline
\end{tabular}

F/U, follow-up; M/F, male/female; N, sample size; Y, year; TM, thalassemia; NTDT, non-transfusion-dependent thalassemia, TDT, transfusion-dependent thalassemia.

assess the pooled ORR and CRR, but also compared the ORR and CRR of the thalidomide group and the placebo group. The pooled ORR was $85 \%$ (95\% CI: $80-90 \%, \mathrm{I}^{2}=38 \%, p=0.07$ ), and the pooled ORR values in two subgroups were different. Seven studies reported the ORR of NTDT patients after the treatment of thalidomide (Chen et al., 2017; Li et al., 2018; Ren et al., 2018; Jain et al., 2019; Sen et al., 2020; Yang et al., 2020; Yassin, 2020), in which the ORR was $91 \%$ (95\% CI: $\left.82-98 \%, \mathrm{I}^{2}=12 \%, p=0.34\right)$. In addition, eight studies reported the ORR of TDT patients after the treatment of thalidomide (ORR, 83\%; 95\% CI: 72-91\%, $\mathrm{I}^{2}=51 \%$, $p=0.05$ ) (Figure 2) (Chen et al., 2017; Li et al., 2018; Nag et al., 2020; Sen et al., 2020; Yang et al., 2020; Yassin, 2020; Chen et al., 2021; Li et al., 2021). Compared with the placebo group, the thalidomide group had higher odds of ORR (odds ratio $=20.4$; 95\% CI: 6.75-61.64) (Supplementary Figure S3) (Chen et al., 2021).

\section{CRR}

CRR was assessed in nine studies (Chen et al., 2017; Li et al., 2018; Begum et al., 2020; Islam et al., 2020; Nag et al., 2020; Yang et al., 2020; Yassin, 2020; Chen et al., 2021; Li et al., 2021). The pooled CRR was 54\% (95\% CI: $31-76 \%, \mathrm{I}^{2}=90 \%, p<0.01$ ). Nine studies reported the CRR of TDT patients after the treatment of thalidomide (Chen et al., 2017; Li et al., 2018; Begum et al., 2020; Islam et al., 2020; Nag et al., 2020; Yang et al., 2020; Yassin, 2020; Chen et al., 2021; Li et al., 2021), in which the CRR was 52\%
(95\% CI: $\left.30-73 \%, \mathrm{I}^{2}=91 \%, p<0.01\right)$. However, only one study reported the CRR of NTDT patients after the treatment of thalidomide (CRR, 100\%; 95\% CI: 0-100\%) (Figure 3) (Chen et al., 2017). In addition, compared with the placebo group, the thalidomide group had higher odds of CRR (odds ratio $=20.4$; 95\% CI: 6.75-61.64) (Supplementary Figure S4) (Chen et al., 2021).

\section{Hb Level (g/dl)}

Eight studies measured $\mathrm{Hb}$ level (Chen et al., 2017; Li et al., 2018; Ren et al., 2018; Begum et al., 2020; Nag et al., 2020; Sen et al., 2020; Yang et al., 2020; Yassin, 2020). The results of meta-analysis showed that after treatment of thalidomide, a statistically significant increase of mean $\mathrm{Hb}$ level from baseline was $1.55 \mathrm{~g} / \mathrm{dl}(95 \% \mathrm{CI}: 1.17-1.92 \mathrm{~g} / \mathrm{dl})$. Heterogeneity was moderate $\left(\mathrm{I}^{2}=51 \%, p=0.03\right)$ (Figure 4).

\section{HbF Level (\%)}

Four studies measured HbF level (Chen et al., 2017; Li et al., 2018; Jain et al., 2019; Yang et al., 2020). The results of meta-analysis showed that after treatment with thalidomide, a statistically significant increase of mean $\mathrm{HbF}$ level from baseline was $0.68 \%$ (95\% CI: $0.33-1.02 \%)$. Heterogeneity was low $\left(\mathrm{I}^{2}=0 \%\right.$, $p=0.43)$ (Figure 5). 


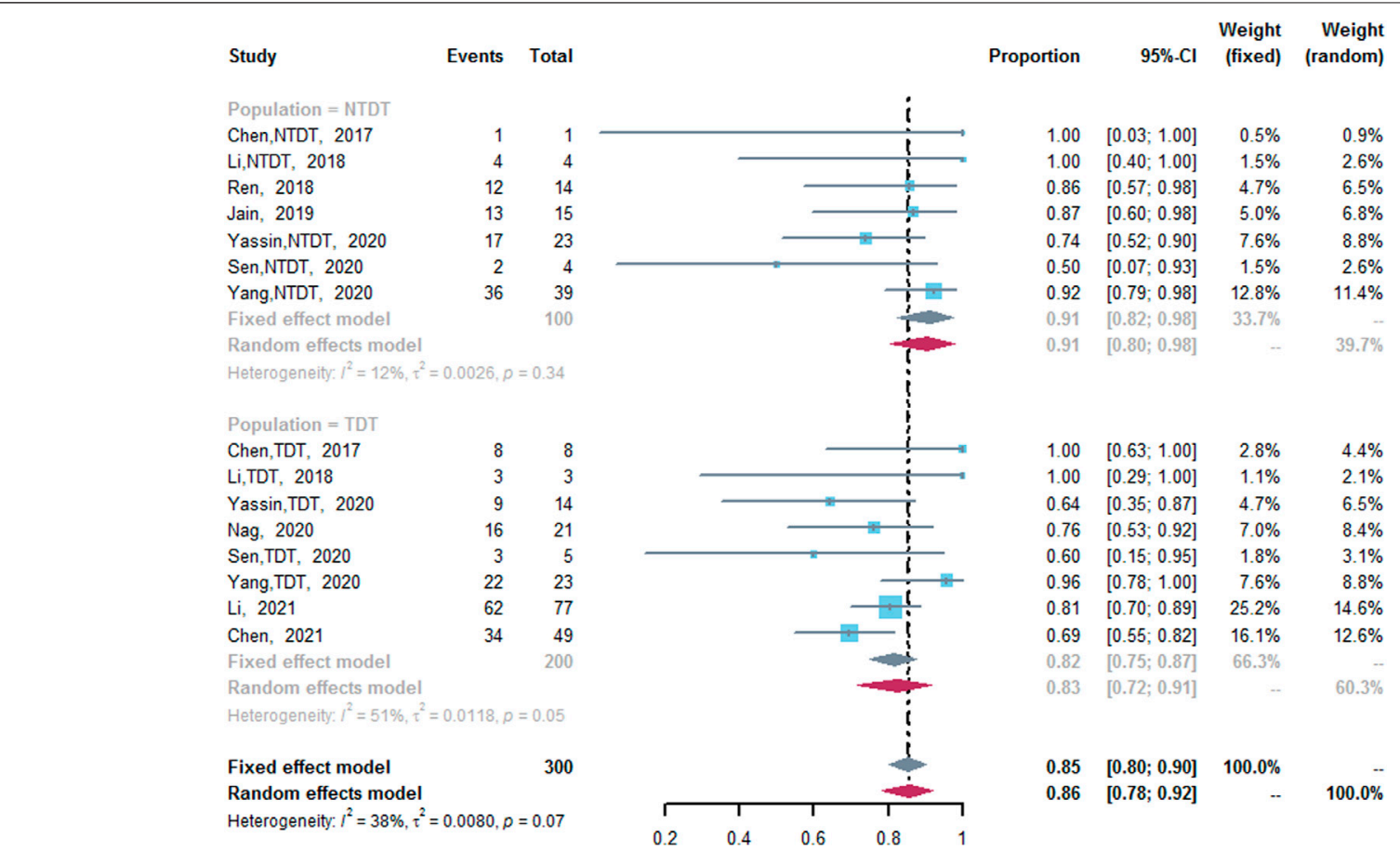

FIGURE 2 | A forest plot illustrating overall response rate in population-based subgroups.

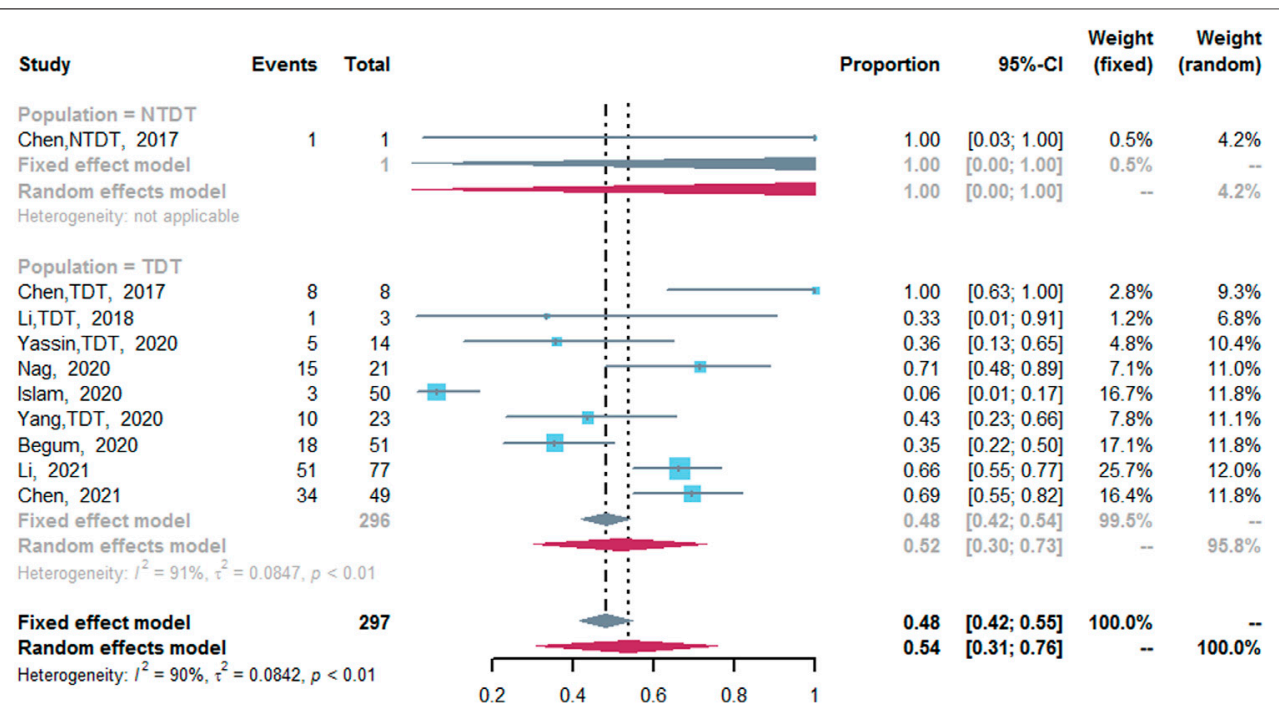

FIGURE 3 | A forest plot illustrating complete response rate in population-based subgroups.

\section{HbA Level (g/dl)}

Two studies measured HbA level (Li et al., 2018; Ren et al., 2018). The results of meta-analysis revealed that after the treatment of thalidomide, the change in $\mathrm{HbA}$ level from baseline was not statistically significant, $0.196 \mathrm{~g} / \mathrm{dl}(95 \% \mathrm{CI}$ : $0.463-0.855 \mathrm{~g} / \mathrm{dl})$. Heterogeneity was low $\left(\mathrm{I}^{2}=0 \%, p=0.42\right)$ (Supplementary Figure S5).

\section{Spleen Length (cm)}

Two studies measured spleen length (Chen et al., 2017; Nag et al., 2020). The results of meta-analysis indicated that after the treatment of thalidomide, the change in spleen length from baseline was not statistically significant, $0.19 \mathrm{~cm}(95 \% \mathrm{CI}$ : $-0.85-1.23 \mathrm{~cm})$. Heterogeneity was moderate $\left(\mathrm{I}^{2}=68 \%, p=\right.$ 0.08) (Supplementary Figure S6). 


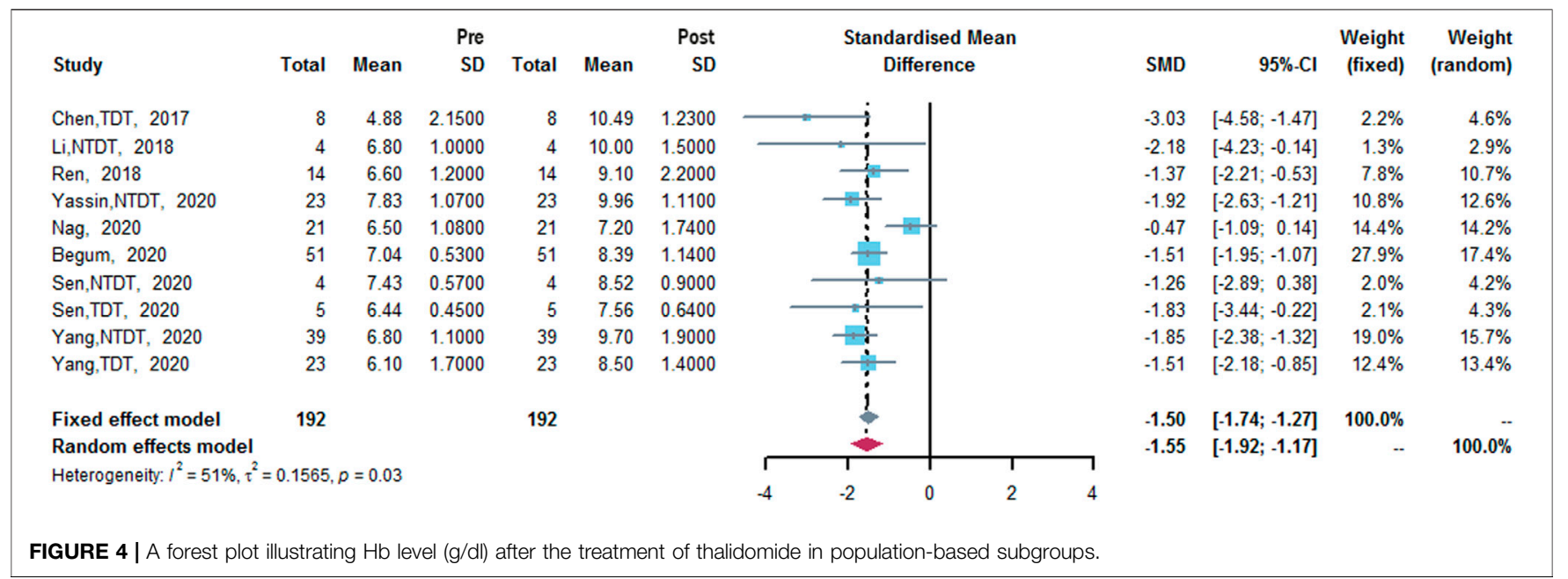

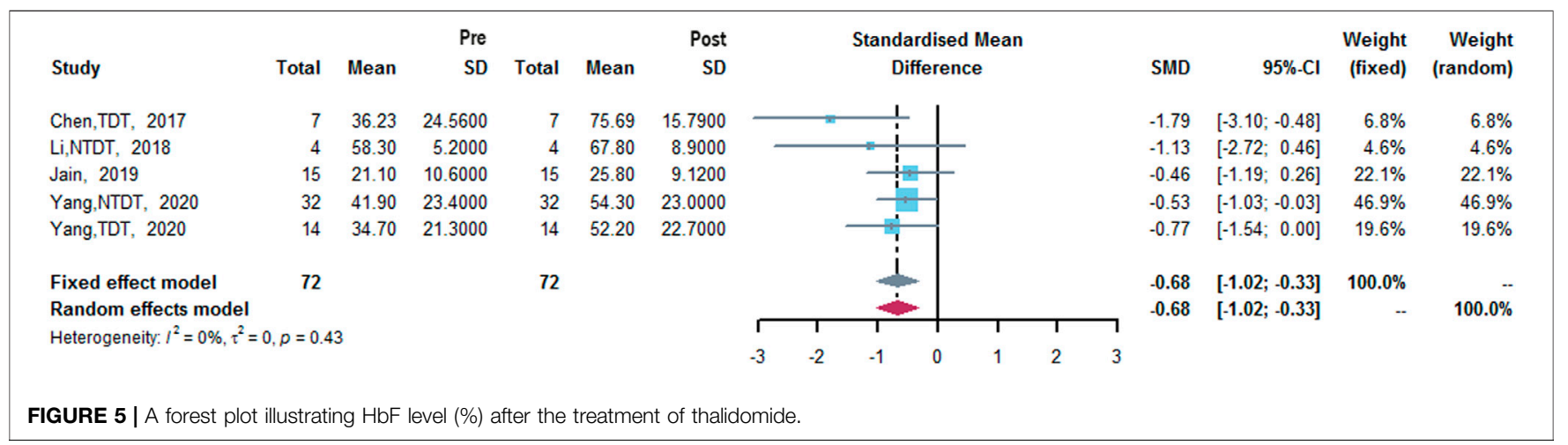

\begin{tabular}{|c|c|c|c|c|c|c|c|c|c|c|c|}
\hline & Study & Events & Total & & & & & Proportion & $95 \%-\mathrm{Cl}$ & $\begin{array}{l}\text { Weight } \\
\text { (fixed) }\end{array}$ & $\begin{array}{r}\text { Weight } \\
\text { (random) }\end{array}$ \\
\hline & Chen, 2017 & 0 & 9 & $\leftleftarrows$ & & & & 0.00 & {$[0.00 ; 0.34]$} & $2.8 \%$ & $8.4 \%$ \\
\hline & Li, 2018 & 2 & 7 & & & & & 0.29 & {$[0.04 ; 0.71]$} & $2.2 \%$ & $7.8 \%$ \\
\hline & Ren, 2018 & 3 & 15 & $\longrightarrow$ & & & & 0.20 & {$[0.04 ; 0.48]$} & $4.5 \%$ & $9.5 \%$ \\
\hline & Yassin, 2020 & 11 & 37 & - & & & & 0.30 & {$[0.16 ; 0.47]$} & $10.9 \%$ & $10.9 \%$ \\
\hline & Nag, 2020 & 10 & 21 & & 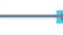 & - & & 0.48 & {$[0.26 ; 0.70]$} & $6.3 \%$ & $10.1 \%$ \\
\hline & Sen, 2020 & 7 & 9 & & & 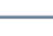 & - & 0.78 & {$[0.40 ; 0.97]$} & $2.8 \%$ & $8.4 \%$ \\
\hline & Yang, 2020 & 10 & 62 & $\rightarrow$ & & & & 0.16 & {$[0.08 ; 0.28]$} & $18.2 \%$ & $11.3 \%$ \\
\hline & Islam, 2020 & 3 & 50 & 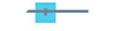 & & & & 0.06 & {$[0.01 ; 0.17]$} & $14.7 \%$ & $11.1 \%$ \\
\hline & Begum, 2020 & 19 & 51 & & $\rightarrow-$ & & & 0.37 & {$[0.24 ; 0.52]$} & $15.0 \%$ & $11.2 \%$ \\
\hline & Li, 2021 & 48 & 77 & & & 1 & & 0.62 & {$[0.51 ; 0.73]$} & $22.6 \%$ & $11.4 \%$ \\
\hline & Fixed effect model & & 338 & & & & & 0.31 & {$[0.26 ; 0.36]$} & $100.0 \%$ & -- \\
\hline & Random effects model & & & -1 & $=$ & & & 0.30 & {$[0.15 ; 0.47]$} & .. & $100.0 \%$ \\
\hline & Heterogeneity: $I^{2}=89 \%, \tau^{2}$ & $=0.0600, p$ & $<0.01$ & 1 & 1 & 1 & $\neg$ & & & & \\
\hline & & & & 0.2 & 0.4 & 0.6 & 0.8 & & & & \\
\hline
\end{tabular}

\section{SF Level (ng/ml)}

Two studies measured SF concentration (Begum et al., 2020; Yang et al., 2020). The results of meta-analysis showed that after the treatment of thalidomide, the change in SF level from baseline was not statistically significant, $0.03 \mathrm{ng} / \mathrm{ml} \quad(95 \%$ CI: $-0.25-0.31 \mathrm{ng} / \mathrm{ml})$. Heterogeneity was moderate $\left(\mathrm{I}^{2}=48 \%, p=\right.$ 0.15) (Supplementary Figure S7).

\section{AEs of Thalidomide}

Ten studies (Chen et al., 2017; Li et al., 2018; Ren et al., 2018; Begum et al., 2020; Islam et al., 2020; Nag et al., 2020; Sen et al., 2020; Yang et al., 2020; Yassin, 2020; Li et al., 2021), which enrolled a total of 338 patients, reported AEs of thalidomide. The results of meta-analysis revealed that about $30 \%$ (95\% CI: $\left.15-47 \%, \mathrm{I}^{2}=89 \%, p<0.01\right)$ of patients suffered from AEs of 
TABLE 2 | Results of sensitive analysis and tests of publication bias.

\begin{tabular}{|c|c|c|c|c|}
\hline Outcome & No. of studies & $\begin{array}{c}\text { Variations in sensitivity } \\
\text { analyses }\end{array}$ & Effects model & $\begin{array}{c}\text { Egger's test for } \\
\text { publication bias ( } p \text { value) }\end{array}$ \\
\hline ORR & 10 & NS & Fixed & 0.818 \\
\hline CRR & 9 & NS & Random & - \\
\hline $\mathrm{Hb}$ level & 8 & S & Random & - \\
\hline HbF level & 4 & NS & Fixed & - \\
\hline HbA level & 2 & NS & Fixed & - \\
\hline Spleen length & 2 & NS & Random & - \\
\hline SF level & 2 & NS & Fixed & - \\
\hline AEs & 10 & NS & Random & 0.818 \\
\hline
\end{tabular}

no Egger's test assessed because the number of included studies was <10; NS: no significant variations introduced; S: significant variations introduced.

thalidomide. Among the included studies, except for three patients with peripheral neurotoxicity and/or headache (Yang et al., 2020; Li et al., 2021), one patient with central venous thrombosis and one patients with seizure (Li et al., 2021), the reported AEs were mild, and common AEs included constipation, somnolence, high alanine aminotransferase (ALT) level, and rash (Figure 6).

\section{Sensitivity Analysis and Publication Bias}

To analyze heterogeneity, we conducted sensitivity analysis of pooled outcomes, and the reliability of pooled outcomes was confirmed, except for $\mathrm{Hb}$ level (Table 2). After removing Nag et al.'s study (Nag et al., 2020), the results showed that the $\mathrm{I}^{2}$ was reduced, with a re-estimated mean change in $\mathrm{Hb}$ level from baseline was $1.68 \mathrm{~g} / \mathrm{dl}$ (95\% CI: $1.42-1.93 \mathrm{~g} / \mathrm{dl}, \mathrm{I}^{2}=0 \%, p=$ 0.69 ) (Supplementary Figure S8). No significant publication bias was identified in Egger's Test (Table 2).

\section{DISCUSSION}

In humans, $\beta$-like-globin genes gradually express $e$-globin gene, $\gamma$-globin gene, and $\gamma$-globin gene at distinct stages of development through a process termed "hemoglobin switching". $\gamma$-globin gene expresses $\gamma$-globin and forms $\mathrm{HbF}$ $\left(\alpha_{2} \gamma_{2}\right)$ with $a$-globin, and $\mathrm{HbF}$ is the most important hemoglobin in early fetal development. Around the time of birth, fetal $\gamma$-globin expression is extinguished and the adult $\gamma$ globin gene is activated (Stamatoyannopoulos, 2005). When carriers have mutant $\beta$-globin gene, the synthesis of $\mathrm{HbA}$ $\left(\alpha_{2} \beta_{2}\right)$ decreases and $a$ globin and $\beta$ globin chains are imbalanced, then the clinical symptoms associated with $\beta$ thalassemia occur. The severity of disease ( $\beta$-thalassemia) expression is mainly related to the degree of the unmatched $a$-globin chain. While scientists observed that $\beta$-thalassemia patients with a high level of $\mathrm{HbF}$ had lower degree of anemia and were mainly diagnosed with NTDT (Winichagoon et al., 2000). Hereditary persistence of fetal hemoglobin (HPFH) is a condition that naturally occurs and is characterized by a considerable elevation of $\mathrm{HbF}$ level in adult red blood cells. Individuals with compound heterozygous $\beta$-thalassemia and
HPFH have milder clinical manifestations (Papadakis et al., 2002). This clinical benefit of increased HbF level leads to the emergence of numbers of $\mathrm{HbF}$ inducers. The earlier $\mathrm{HbF}$ inducers include hydroxyurea, DNA methyltransferase (DNMT) inhibitor, histone deacetylase inhibitor agents (Witt et al., 2003; Olivieri et al., 2011; Karimi et al., 2021). Hydroxyurea is the most widely used $\mathrm{HbF}$ inducer in patients with moderate and severe $\beta$-thalassemia (Gambari and Fibach, 2007; Testa, 2009). A number of studies demonstrated that hydroxyurea appears to be effective, well tolerated, and associated with mild and transient adverse events for thalassemia patients (Haghpanah et al., 2018; Karimi et al., 2021). Some studies also reported that the efficacy of hydroxyurea declined in hematological response after treatment for 12 months (Mancuso et al., 2006; Rigano et al., 2010). DNMT inhibitors and histone deacetylase inhibitors were mainly tested in vitro or clinical trials and their safety and efficacy have not been widely demonstrated (Shearstone et al., 2016; Kalantri et al., 2018).

Now, thalidomide, as a novel $\mathrm{HbF}$ inducer, is an emerging treatment option for $\beta$-thalassemia. A number of scholars pointed out that thalidomide induced $\gamma$-globin mRNA expression in a dose-dependent manner, while it had no effect on $\beta$-globin expression (Aerbajinai et al., 2007). Several small case series and clinical trials (12 single-arm and 3 randomized controlled trials) have reported the efficacy and safety of thalidomide in patients with $\beta$ thalassemia (Chen et al., 2017; Kalra et al., 2017; Li et al., 2018; Ren et al., 2018; Jain et al., 2019; Ricchi et al., 2019; Begum et al., 2020; Islam et al., 2020; Javed et al., 2020; Nag et al., 2020; Sen et al., 2020; Yang et al., 2020; Yassin, 2020; Chandra et al., 2021; Chen et al., 2021; Jain et al., 2021; Li et al., 2021). Chen et al. conducted the largest prospective study enrolled 99 patients has shown remarkable response to thalidomide treatment for patients with $\beta$-thalassemia (Chen et al., 2021). Based on these studies, we conducted the present meta-analysis. According to the results, thalidomide increased $\mathrm{Hb}$ level by elevating $\mathrm{HbF}$ level, and the clinical symptoms of patients with $\beta$-thalassemia were improved after treatment, which were consistent with previous studies (Fard et al., 2014). Furthermore, the 
efficacy of thalidomide for treating $\beta$-thalassemia was markedly higher than that of hydroxyurea (Algiraigri et al., 2017a; Algiraigri et al., 2017b), and several included studies with the follow-up over 12 months demonstrated the stable efficacy of thalidomide (Islam et al., 2020; Yang et al., 2020; Yassin, 2020; Chen et al., 2021). About the effective dose of thalidomide, the included studies were given doses of thalidomide from 50 to $200 \mathrm{mg} /$ day, while there was no obvious differences in increasing $\mathrm{Hb}$ level and improving clinical symptoms for $\beta$-thalassemia between dose of $50 \mathrm{mg} /$ $\mathrm{d}$ and $200 \mathrm{mg} / \mathrm{d}$ (Chen et al., 2017), and enormous doses of thalidomide can cause significant side effects, therefore, the low toxicity dose of $50 \mathrm{mg} / \mathrm{d}$ of thalidomide will meet the goal of improving anemia in patients with thalassemia clinically (Chen et al., 2017; Li et al., 2018; Ren et al., 2018; Jain et al., 2019; Islam et al., 2020; Nag et al., 2020; Sen et al., 2020; Yang et al., 2020). Interestingly, there was narrow difference of ORR between NTDT and TDT patients in this meta-analysis (91 versus $83 \%$ ), and about $52 \%$ of TDT patients became completely transfusion free. It showed remarkable efficacy of thalidomide in TDT patients, and similar result was observed in the latest RCT study, which was encouraging. So we analyzed 30 TDT patients from three studies and found that the most frequent $\beta$-globin gene mutations were CD41-42 (-TCTT) (63\%) (Supplementary Table S2) (Chen et al., 2017; Li et al., 2018; Yang et al., 2020), while the efficacy of thalidomide in TDT patients did not show any statistically significant relationship with XmnI polymorphism or CD41-42 $(-$ TCTT) mutation $(p>0.05)$ (Supplementary Table S3). In the future, further large sample RCTs are needed to demonstrate the efficacy of thalidomide in TDT patients. After thalidomide treatment, although most AEs were mild and tolerable, considering the serious AEs of thalidomide such as embryotoxicity, careful consideration should be given to the use of thalidomide in young women and children, and to ensure that women have strict contraception during treatment. In addition, clinical symptoms of patients with $\beta$-thalassemia were significantly improved, while in most studies the effect of thalidomide on $\mathrm{Hb}$ and $\mathrm{HbF}$ level appeared to be rather modest. Regarding the mechanisms of thalidomide in $\beta$-thalassemia are still unclear, and Chen et al. demonstrated that thalidomide might not only have efficacy in $\mathrm{HbF}$ but also affect erythropoiesis at multiple stages (Chen et al., 2021). So it is necessary to extract the effective components of thalidomide and identify the key mechanisms of thalidomide in the effective treatment of thalassemia. Pomalidomide, a third-generation immunomodulatory drug with less AEs, has been proved to be a strong $\mathrm{HbF}$ inducer (Khamphikham et al., 2020). If more effective and less embryotoxic thalidomide derivatives are developed, it will be widly used and benefit more thalassemia patients. To sum up, it is the first meta-analysis that confirmed the efficacy and safety of thalidomide preliminarily, which could improve prognosis and quality of life in patients with $\beta$-thalassemia by increasing $\mathrm{Hb}$ level.

Regarding the possible mechanisms of thalidomide inducing the expression of $\gamma$-globin gene, a number of studies have shown that it might enhance erythroid transcription factors (e.g., GATAbinding factor 1 (GATA-1)) and inhibit inflammatory factors (e.g., tumor necrosis factor- $\alpha$ (TNF- $\alpha$ )) to increase the production of intracellular reactive oxygen species (ROS) (Amirshahrokhi and Khalili, 2015; Jalali Far et al., 2016). Then, increased production of ROS-mediated p38 MAPK signaling and histone $\mathrm{H} 4$ acetylation induces $\gamma$-globin gene expression (Aerbajinai et al., 2007). Furthermore, it has been reported that thalidomide could effectively induce $\gamma$-globin by promoting the proliferation of immature erythroid cells and slowing down erythroid differentiation (Parseval et al., 2008). Recently, in vitro studies using the thalidomide derivative pomalidomide suggested that reduced expression of the transcriptional repressor BCL11A could improve the expression of HbF (Dulmovits et al., 2016; Peslak et al., 2020). With the increase of HbF level, the formation of free $a$-globin chain decreases, alleviating the imbalanced relationship between $a$-globin chain and $\beta$-globin chain in $\beta$-thalassemia patients, so as to improve the clinical symptoms of $\beta$-thalassemia patients.

The present study contains a few limitations. First, most studies included in this meta-analysis were single-arm trials with a small sample size, and almost half studies were conducted in China. Second, there was a moderate-to-severe heterogeneity among the included studies. Considering that there was no significant correlation between the genotype and phenotype of $\beta$-thalassemia, as well as blood transfusion requirements, other factors, which were not assessed in this study, might be the source of heterogeneity. Third, we did not observed a statistically significant change in SF and spleen length in this meta-analysis. Last but not least, the optimal maintenance dose and median thalidomide treatment time remained elusive. Thus, further long-term, and high-quality prospective trials are required to eliminate the abovementioned deficiencies and to confirm long-term safety and efficacy of thalidomide more reliably.

\section{CONCLUSION}

In summary, we, for the first time, conducted this metaanalysis to evaluate the efficacy and safety of thalidomide in the treatment of patients with $\beta$-thalassemia. The results showed that thalidomide could be a relatively safe and evidently effective therapy to reduce the blood transfusion requirements and increase $\mathrm{Hb}$ level in patients with $\beta$ thalassemia, confirming its role as a promising $\mathrm{HbF}$ inducer. Extracting the effective components of thalidomide and identify the key mechanisms of thalidomide in the effective treatment of thalassemia will improve its clinical use in $\beta$-thalassaemia management.

\section{DATA AVAILABILITY STATEMENT}

The original contributions presented in the study are included in the article/Supplementary Material, further inquiries can be directed to the corresponding authors. 


\section{AUTHOR CONTRIBUTIONS}

YL performed literature search, article selection, analysis, manuscript writing and manuscript revising; $\mathrm{ZW}$ performed literature search, article selection, and manuscript writing; GY assisted with analysis, and manuscript review and revision; RL and YL conceived of the study, reviewed and revised the manuscript.

\section{FUNDING}

This work was supported by the National Natural Science Foundation of China (81960028 and 82060029).

\section{REFERENCES}

Aerbajinai, W., Zhu, J., Gao, Z., Chin, K., and Rodgers, G. P. (2007). Thalidomide Induces Gamma-Globin Gene Expression through Increased Reactive Oxygen Species-Mediated P38 MAPK Signaling and Histone H4 Acetylation in Adult Erythropoiesis. Blood 110 (8), 2864-2871. doi:10.1182/blood-2007-01-065201

Algiraigri, A. H., Wright, N. A. M., Paolucci, E. O., and Kassam, A. (2017a). Hydroxyurea for Lifelong Transfusion-dependent $\beta$-thalassemia: A MetaAnalysis. Pediatr. Hematol. Oncol. 34 (8), 435-448. doi:10.1080/ 08880018.2017.1354948

Algiraigri, A. H., Wright, N. A. M., Paolucci, E. O., and Kassam, A. (2017b). Hydroxyurea for Nontransfusion-dependent $\beta$-thalassemia: A Systematic Review and Meta-Analysis. Hematol. Oncol. Stem Cel Ther 10 (3), 116-125. doi:10.1016/j.hemonc.2017.02.002

Amirshahrokhi, K., and Khalili, A. R. (2015). The Effect of Thalidomide on Ethanol-Induced Gastric Mucosal Damage in Mice: Involvement of Inflammatory Cytokines and Nitric Oxide. Chem. Biol. Interact 225, 63-69. doi:10.1016/j.cbi.2014.11.019

Angastiniotis, M., and Modell, B. (1998). Global Epidemiology of Hemoglobin Disorders. Ann. N. Y Acad. Sci. 850, 251-269. doi:10.1111/j.17496632.1998.tb10482.x

Begum, M., Moslem, Md. M. H., Begum, N. N. F., and Rahman, Md. Z. (2020). Outcome of Treatment with Thalidomide in Transfusion Dependent Thalassemia Patients: A Prospective Study in a Thalassemia Center, Dhaka, Bangladesh. Am. J. Pediatr. 6 (3), 168-171. doi:10.11648/j.ajp.20200603.11

Chandra, J., Parakh, N., Sidharth, Singh, N., Sharma, S., Goel, M., et al. (2021). Efficacy and Safety of Thalidomide in Patients with Transfusion-dependent Thalassemia. Indian Pediatr. 58 (7), 611-616. doi:10.1007/s13312-021-2254-y

Chen, J., Zhu, W., Cai, N., Bu, S., Li, J., and Huang, L. (2017). Thalidomide Induces Haematologic Responses in Patients with $\beta$-thalassaemia. Eur. J. Haematol. 99 (5), 437-441. doi:10.1111/ejh.12955

Chen, J. M., Zhu, W. J., Liu, J., Wang, G. Z., Chen, X. Q., Tan, Y., et al. (2021). Safety and Efficacy of Thalidomide in Patients with Transfusion-dependent $\beta$ thalassemia: a Randomized Clinical Trial. Signal. Transduct Target. Ther. 6 (1), 405. doi:10.1038/s41392-021-00811-0

Dulmovits, B. M., Appiah-Kubi, A. O., Papoin, J., Hale, J., He, M., Al-Abed, Y., et al. (2016). Pomalidomide Reverses $\gamma$-globin Silencing through the Transcriptional Reprogramming of Adult Hematopoietic Progenitors. Blood 127 (11), 1481-1492. doi:10.1182/blood-2015-09-667923

Fard, A. D., Kaviani, S., Noruzinia, M., Saki, N., and Mortaz, E. (2014). Induction of Fetal Hemoglobin as a Novel Therapeutic Strategy for $\beta$-hemoglobinopathy. Lab. Hematol. 20 (1), 1. doi:10.1532/lh96.12015

Gambari, R., and Fibach, E. (2007). Medicinal Chemistry of Fetal Hemoglobin Inducers for Treatment of Beta-Thalassemia. Curr. Med. Chem. 14 (2), 199-212. doi:10.2174/092986707779313318

Haghpanah, S., Zarei, T., Eshghi, P., Zekavat, O., Bordbar, M., Hoormand, M., et al. (2018). Efficacy and Safety of Resveratrol, an Oral Hemoglobin F-Augmenting

\section{ACKNOWLEDGMENTS}

We would like to extend a special thanks to Xiaolin Yin (Department of Hematology, The 923rd Hospital of the Joint Logistics Support Force of the Peoples Liberation Army, China) who provided access to the individual patient data for an included trial.

\section{SUPPLEMENTARY MATERIAL}

The Supplementary Material for this article can be found online at: https:/www.frontiersin.org/articles/10.3389/fphar.2021.814302/ full\#supplementary-material

Agent, in Patients with Beta-Thalassemia Intermedia. Ann. Hematol. 97 (10), 1919-1924. doi:10.1007/s00277-018-3392-8

Islam, A., Mahfuz, D. C. H., Ara, D. T., Telfer, D. P., Dokal, P. I., Allard, D. S., et al. (2020). Effectiveness of Thalidomide in Transfusion Dependent Thalassemia Patients where Transfusion and Chelation Are Challenging with Alarming High Incidence of Transfusion Transmitted Infection. HemaSphere 4, 1058. doi:10.1097/HS9.0000000000000404

Jain, M., Chakrabarti, P., Dolai, T. K., Ghosh, P., Mandal, P. K., Baul, S. N., et al. (2021). Comparison of Efficacy and Safety of Thalidomide vs Hydroxyurea in Patients with Hb E- $\beta$ Thalassemia - a Pilot Study from a Tertiary Care Centre of India. Blood Cell Mol Dis 88, 102544. doi:10.1016/j.bcmd.2021.102544

Jain, M., De, R., Jitani, A., Chakrabarti, P., Mondal, P. K., Baul, S., et al. (2019). Efficacy of Thalidomide and Hydroxyurea as HB F Inducer in Non-transfusion Dependent Thalassemia. Indian J. Hematol. Blood Transfus. 35 (1), S54. doi:10.1007/s12288-019-01207-5

Jalali Far, M. A., Dehghani Fard, A., Hajizamani, S., Mossahebi-Mohammadi, M., Yaghooti, H., and Saki, N. (2016). Thalidomide Is More Efficient Than Sodium Butyrate in Enhancing GATA-1 and EKLF Gene Expression in Erythroid Progenitors Derived from HSCs with $\beta$-globin Gene Mutation. Int. J. Hematol. Oncol. Stem Cel Res 10 (1), 37-41.

Javed, R., Radhakrishnan, V., Basu, S., and Chandy, M. (2020). Challenges in Transfusion and the Role of Thalidomide in E- $\beta$-Thalassemia-A Case Report. Clin. Case Rep. 8 (11), 2208-2210. doi:10.1002/ccr3.3141

Kalantri, S. A., Ray, R., Chattopadhyay, A., Bhattacharjee, S., Biswas, A., and Bhattacharyya, M. (2018). Efficacy of Decitabine as Hemoglobin F Inducer in HbE/ $\beta$-Thalassemia. Ann. Hematol. 97 (9), 1689-1694. doi:10.1007/s00277018-3357-y

Kalra, M., Khanna, V. K., Trehan, A., and Mahajan, A. (2017). Thalidomide in Transfusion Dependent Thalassemia: Hope or Hype. J. Pediatr. Hematol. Oncol. 39 (6), 485. doi:10.1097/mph.0000000000000900

Karimi, M., Zarei, T., Bahmanimehr, A., Aramesh, A., Daryanoush, S., and Haghpanah, S. (2021). Long-term Safety and Efficacy of Hydroxyurea in Patients with Non-transfusion-dependent $\beta$-thalassemia: a Comprehensive Single-center Experience. Ann. Hematol. 100 (12), 2901-2907. doi:10.1007/ s00277-021-04627-4

Khamphikham, P., Nualkaew, T., Pongpaksupasin, P., Kaewsakulthong, W., Songdej, D., Paiboonsukwong, K., et al. (2020). High-level Induction of Fetal Haemoglobin by Pomalidomide in $\beta$-thalassaemia/HbE Erythroid Progenitor Cells. Br. J. Haematol. 189 (6), e240-e245. doi:10.1111/bjh.16670

Li, X., Hu, S., Liu, Y., Huang, J., Hong, W., Xu, L., et al. (2021). Efficacy of Thalidomide Treatment in Children with Transfusion Dependent $\beta$ Thalassemia: A Retrospective Clinical Study. Front. Pharmacol. 12, 722502. doi:10.3389/fphar.2021.722502

Li, Y., Ren, Q., Zhou, Y., Li, P., Lin, W., and Yin, X. (2018). Thalidomide Has a Significant Effect in Patients with Thalassemia Intermedia. Hematology 23 (1), 50-54. doi:10.1080/10245332.2017.1354427

Mancuso, A., Maggio, A., Renda, D., Di Marzo., R., and Rigano, P. (2006). Treatment with Hydroxycarbamide for Intermedia Thalassaemia: Decrease 
of Efficacy in Some Patients during Long-Term Follow up. Br. J. Haematol. 133 (1), 105-106. doi:10.1111/j.1365-2141.2006.06002.x

Modell, B., and Darlison, M. (2008). Global Epidemiology of Haemoglobin Disorders and Derived Service Indicators. Bull. World Health Organ. 86 (6), 480-487. doi:10.2471/blt.06.036673

Moutouh-de Parseval, L. A., Verhelle, D., Glezer, E., Jensen-Pergakes, K., Ferguson, G. D., Corral, L. G., et al. (2008). Pomalidomide and Lenalidomide Regulate Erythropoiesis and Fetal Hemoglobin Production in Human CD34+ Cells. J. Clin. Invest. 118 (1), 248-258. doi:10.1172/ jci32322

Nag, A., Radhakrishnan, V. S., Kumar, J., Bhave, S., Mishra, D. K., Nair, R., et al. (2020). Thalidomide in Patients with Transfusion-dependent E-Beta Thalassemia Refractory to Hydroxyurea: A Single-Center Experience. Indian J. Hematol. Blood Transfus. 36 (2), 399-402. doi:10.1007/s12288-020-01263-2

Olivieri, N. F., Saunthararajah, Y., Thayalasuthan, V., Kwiatkowski, J., Ware, R. E., Kuypers, F. A., et al. (2011). A Pilot Study of Subcutaneous Decitabine in $\beta$ thalassemia Intermedia. Blood 118 (10), 2708-2711. doi:10.1182/blood-201103-341909

Papadakis, M. N., Patrinos, G. P., Tsaftaridis, P., and Loutradi-Anagnostou, A. (2002). A Comparative Study of Greek Nondeletional Hereditary Persistence of Fetal Hemoglobin and Beta-Thalassemia Compound Heterozygotes. J. Mol. Med. (Berl) 80 (4), 243-247. doi:10.1007/s00109-001-0312-4

Peslak, S. A., Khandros, E., Huang, P., Lan, X., Geronimo, C. L., Grevet, J. D., et al. (2020). HRI Depletion Cooperates with Pharmacologic Inducers to Elevate Fetal Hemoglobin and Reduce Sickle Cell Formation. Blood Adv. 4 (18), 4560-4572. doi:10.1182/bloodadvances.2020002475

Ren, Q., Zhou, Y. L., Wang, L., Chen, Y. S., Ma, Y. N., Li, P. P., et al. (2018). Clinical Trial on the Effects of Thalidomide on Hemoglobin Synthesis in Patients with Moderate Thalassemia Intermedia. Ann. Hematol. 97 (10), 1933-1939. doi:10.1007/s00277-018-3395-5

Ricchi, P., Costantini, S., Spasiano, A., Cinque, P., Di Matola, T., Ammirabile, M., et al. (2019). Rechallenging to Hydroxycarbamide Post Thalidomide Treatment and Response in a Non Transfusion-dependent Patient, Is it Possible? Indian J. Hematol. Blood Transfus. 35 (3), 587-589. doi:10.1007/s12288-019-01093-x

Rigano, P., Pecoraro, A., Calzolari, R., Troia, A., Acuto, S., Renda, D., et al. (2010). Desensitization to Hydroxycarbamide Following Long-Term Treatment of Thalassaemia Intermedia as Observed In Vivo and in Primary Erythroid Cultures from Treated Patients. Br. J. Haematol. 151 (5), 509-515. doi:10.1111/j.1365-2141.2010.08397.x

Sen, A., Dolai, T. K., and Mandal, P. K. (2020). Efficacy and safety of thalidomide in HB e beta thalassemia. HemaSphere 4, 1064. doi:10.1097/HS9.0000000000000404

Shearstone, J. R., Golonzhka, O., Chonkar, A., Tamang, D., van Duzer, J. H., Jones, S. S., et al. (2016). Chemical Inhibition of Histone Deacetylases 1 and 2 Induces Fetal
Hemoglobin through Activation of GATA2. PLoS One 11 (4), e0153767. doi:10.1371/journal.pone.0153767

Stamatoyannopoulos, G. (2005). Control of Globin Gene Expression during Development and Erythroid Differentiation. Exp. Hematol. 33 (3), 259-271. doi:10.1016/j.exphem.2004.11.007

Suragani, R. N., Cadena, S. M., Cawley, S. M., Sako, D., Mitchell, D., Li, R., et al. (2014). Transforming Growth Factor- $\beta$ Superfamily Ligand Trap ACE-536 Corrects Anemia by Promoting Late-Stage Erythropoiesis. Nat. Med. 20 (4), 408-414. doi:10.1038/nm.3512

Testa, U. (2009). Fetal Hemoglobin Chemical Inducers for Treatment of Hemoglobinopathies. Ann. Hematol. 88 (6), 505-528. doi:10.1007/ s00277-008-0637-y

Winichagoon, P., Fucharoen, S., Chen, P., and Wasi, P. (2000). Genetic Factors Affecting Clinical Severity in Beta-Thalassemia Syndromes. J. Pediatr. Hematol. Oncol. 22 (6), 573-580. doi:10.1097/00043426-200011000-00026

Witt, O., Monkemeyer, S., Rönndahl, G., Erdlenbruch, B., Reinhardt, D., Kanbach, K., et al. (2003). Induction of Fetal Hemoglobin Expression by the Histone Deacetylase Inhibitor Apicidin. Blood 101 (5), 2001-2007. doi:10.1182/blood-2002-08-2617

Yang, K., Wu, Y., Zhou, Y., Long, B., Lu, Q., Zhou, T., et al. (2020). Thalidomide for Patients with $\beta$-Thalassemia: A Multicenter Experience. Mediterr. J. Hematol. Infect. Dis. 12, e2020021. doi:10.4084/mjhid.2020.021

Yassin, A. K. (2020). Promising Response to Thalidomide in Symptomatic $\beta$ Thalassemia. Indian J. Hematol. Blood Transfus. 36 (8), 337-341. doi:10.1007/s12288-019-01231-5

Conflict of Interest: The authors declare that the research was conducted in the absence of any commercial or financial relationships that could be construed as a potential conflict of interest.

Publisher's Note: All claims expressed in this article are solely those of the authors and do not necessarily represent those of their affiliated organizations, or those of the publisher, the editors and the reviewers. Any product that may be evaluated in this article, or claim that may be made by its manufacturer, is not guaranteed or endorsed by the publisher.

Copyright $\odot 2022 \mathrm{Lu}$, Wei, Yang, Lai and Liu. This is an open-access article distributed under the terms of the Creative Commons Attribution License (CC BY). The use, distribution or reproduction in other forums is permitted, provided the original author(s) and the copyright owner(s) are credited and that the original publication in this journal is cited, in accordance with accepted academic practice. No use, distribution or reproduction is permitted which does not comply with these terms. 